\title{
Histological and cytochemical indices of toxic injury in the liver of dab Limanda limanda
}

\author{
Angela Köhler, Heike Deisemann, Bjarne Lauritzen
}

Biologische Anstalt Helgoland/Zentrale, Notkestrasse 31, W-2000 Hamburg 52, Germany

\begin{abstract}
Lysosomes play a key role in normal cellular catabolism and during the accumulation and detoxification of different classes of anthropogenic substances. As a contribution to the Bremerhaven Workshop, cytochemical measurements of the integrity of the lysosomal compartment, histopathology and electron microscopy were made on the liver of dab Limanda limanda during spawning time along a pollution gradient in the German Bight. The aim of the study was to test if lysosomal responses are able to reflect early tissue lesions and their progression during the span of the reproductive processes. Lysosomal perturbations in dab liver indicated early tissue lesions independently of the stage of gonadal development by the intralysosomal accumulation of unsaturated neutral lipids. Impairment of the lysosomal membrane stability sensitively reflected the progression towards liver degeneration. Significant differences with respect to lysosomal membrane stability, pathological lipid accumulation and liver histopathology were found along the North Sea transect.
\end{abstract}

\section{INTRODUCTION}

The liver of teleosts is a multifunctional organ responsible for food conversion, production of the yolk precursor-protein 'vitellogenin' during gonadal growth, and detoxification of foreign compounds (Emmerson \& Emmerson 1976, Storch et al. 1983, Braunbeck et al. 1989, Hinton \& Lauren 1990, Hogstrand \& Haux 1991, Stegeman \& Lech 1991). Therefore, death of large areas of the liver parenchyma or transformation into neoplasms may result in impairment of the health of the organism including its reproductive abilities. In order to follow the precautionary principle in biological effects monitoring programs, sensitive biological methods are essential for the identification of early changes preceding preneoplastic and neoplastic liver lesions. For application in international monitoring programmes the biological techniques have to be fast, responsive and cost-effective.

Lysosomes are able to accumulate and sequester a wide range of both organic and inorganic compounds (Allison 1969, Staiger 1974, Moore 1985, 1988). Injury to lysosomes may occur by overloading the storage capacity or direct damage to the lysosomal membrane by toxic compounds or oxyradical formation during biotransformation of certain xenobiotics (Diazani \&
Ugazio 1978, Malins et al. 1988, Winston 1991). Due to their central function in cell catabolism by recycling and degrading both endogeneous and exogeneous macromolecules, the impairment of lysosomal function may lead to severe metabolic disorders and finally to pathological events. Cytochemical techniques measuring lysosomal perturbations were applied to dab Limanda limanda in March 1990 during the Bremerhaven Workshop. Cell and tissue pathologies were diagnosed in parallel in order to test if lysosomal perturbations can reflect liver lesions in dab along a German Bight transect of a suspected contaminant gradient from the mouth of the river Elbe to the eastern side of the Dogger Bank.

\section{MATERIALS AND METHODS}

In March 1990 female dab between 20 and $25 \mathrm{~cm}$ total length were sampled aiong the German Bight transect at 7 stations $(1,3,5,6,7,8,9)$. At each station, 25 non-overtly diseased individuals were immediately dissected on board. Macroscopic inspection of the liver included liver discolouration (colour table with numerical order from brown to cream) and registration of number and size of liver nodules. Nodules $>2 \mathrm{~mm}$ 
were recorded according to the ICES recommendations (Anon. 1989). Additionally, nodules $<2 \mathrm{~mm}$ were registered. The majority of dab of the size group investigated showed evidence for gonadal maturation or spawning at all stations. Stages of gonadal development were determined macroscopically after Bückmann (1929), and included the criteria growth and colour of gonads, shape and colour of eggs dependent on yolk incorporation and amount of ripe eggs. The stages ranged from initial egg development in stage 3 to spawning in stage 6 .

Pieces of the central liver lobe $(5 \times 5 \times 5 \mathrm{~mm})$ near the portal vein were quenched in $n$-hexane $\left(-70^{\circ} \mathrm{C}\right)$, cooled in liquid nitrogen for cytochemistry and stored on dry ice. Duplicate serial sections cut at $-25^{\circ} \mathrm{C}$ with a Reichert-Jung cryostat were treated according to Bitensky et al. (1973) and Moore (1976) for the determination of lysosomal stability. For the implementation of the lysosomal stability test in dab liver, shorter intervals of acid labilisation were used $(0,2,4,6,8,10$, $15 \mathrm{~min}$ ) and extended in $5 \mathrm{~min}$ steps up to $45 \mathrm{~min}$. The enzyme $\beta$ - $N$-acetylhexosamidase was selected as a characteristic lysosomal marker enzyme. The serial sections were incubated with the substrate naphthol AS-BI-N-acetyl- $\beta$-D-glucosaminide (Sigma) at $37{ }^{\circ} \mathrm{C}$ in a shaking water bath for $15 \mathrm{~min}$; subsequently the reaction product was detected by a diazo-coupling with Fast Violet $B$ (Serva) for $15 \mathrm{~min}$ at $4{ }^{\circ} \mathrm{C}$. The membrane destabilisation time (maximum staining intensity) was determined as the period of acid labilisation $(0,2,4,6$ to $45 \mathrm{~min}$ ) required to fully destabilise the lysosomal membrane, so that the substrate could penetrate into the lysosome and react with the lysosomal enzyme (Moore et al. 1978, Köhler 1990).

Unsaturated neutral lipids were stained with Oil Red $O$ (Bancroft 1967) and microscopically graded from 0 to 7 using representative micrographs; this grading was based on density measurements of the staining product with a photometer microscope (Zeiss).

For light microscopic studies liver pieces $(5 \times 5 \times$ $10 \mathrm{~mm}$ ) adjacent to those dissected for cytochemistry were fixed in $4 \%$ Bakers formol for $24 \mathrm{~h}$ at $4{ }^{\circ} \mathrm{C}$, rinsed twice in phosphate buffer (30 min each) and de- hydrated in $70 \%(30 \mathrm{~min})$ and $100 \%$ acetone $(2 \times 30$ min $)$. Tissues were embedded in methacrylate (Serva), and sections of $2 \mu \mathrm{m}$ were cut on a rotation microtome (Sorvall JB 4) and stained with H\&E (Harris).

For electron microscopy small cubes of the central lobe of the liver and additionally of grossly visible nodules were fixed in $5 \%$ glutaraldehyde on ice, postfixed in $2 \%$ osmium tetroxide $(3 \mathrm{~h})$ and embedded in Epon after dehydration. Ultrathin sections were stained with saturated uranyl acetate (in 100\% methanol, 5 min) and with lead citrate (according to Reynolds) for $1.5 \mathrm{~min}$ for diagnosis in a TEM (Zeiss 109). For detailed examination of foci of altered cells, the lesions were identified in toluidine-blue stained semi-thin sections before cutting ultra-thin sections. Ultra-thin sections of juvenile dab were prepared for comparison of liver ultrastructure during gonadal rest and maturation.

Classification of lesions in dab liver were based on generally accepted criteria used in other flatfish species and mammals including the description of early to degenerative, preneoplastic and neoplastic lesions (Pierce et al. 1978, Frith \& Ward 1980, Malins et al. 1985, Malins et al. 1987, Myers et al. 1987, Hinton et al. 1988, Bannasch et al. 1989). Regularly co-occurring liver changes were summarized and staged according to their pathological relevance and expansion in the liver tissue. During histological examination the presence of apoptotic bodies ('Councilman bodies') was estimated in a semi-quantitative manner $(-=0, \pm=<5$, $++=10$ ) in each of 10 readings per liver section.

For the statistical evaluation of the data only nonparametric distribution-free tests were chosen (Spearman's rank correlation; Kruskal-Wallis $H$-test). Significances were accepted with a >95\% level of confidence.

\section{RESULTS}

\section{Histology of dab liver}

Livers of spawning dab showed a significant decrease in cytoplasmic lipid content compared to immature dab and changes in the intracellular organisation.

Fig. 1 Limanda limanda. Ultrastructure of dab liver. (A) Healthy liver of dab during gonadal maturation with well-developed rough endoplasmic reticulum (rer), highly activated Golgi complexes (gc) and electron-dense vesicles (arrows). (B) Proliferation of smooth endoplasmic reticulum (ser) and extreme enlargement of endocytic vacuoles (v) fusing with lipid droplets (li, arrow). (C) Small basophilic hepatocytes close to necrotic perisinusoidal areas; note enormous proliferation of rough endoplasmic reticulum (rer) and increased nucleus/cytoplasm relationship. (D) Intensive endocytosis of small particles (lipoproteins, $\star$ ) via marginal infoldings (arrows) of the endothelium (en) from the blood vessel into hepatocytes. (E) Transition of parallelly orientated stacks of rer in phenotypically altered basophilic hepatocytes into circular and sinuous profiles of rer (arrows). ( $F$ ) Section of a

larger area (nodule?) composed of hepatocytes with numerous nuclei (n) and filled with circular and sinuous profiles of rer 

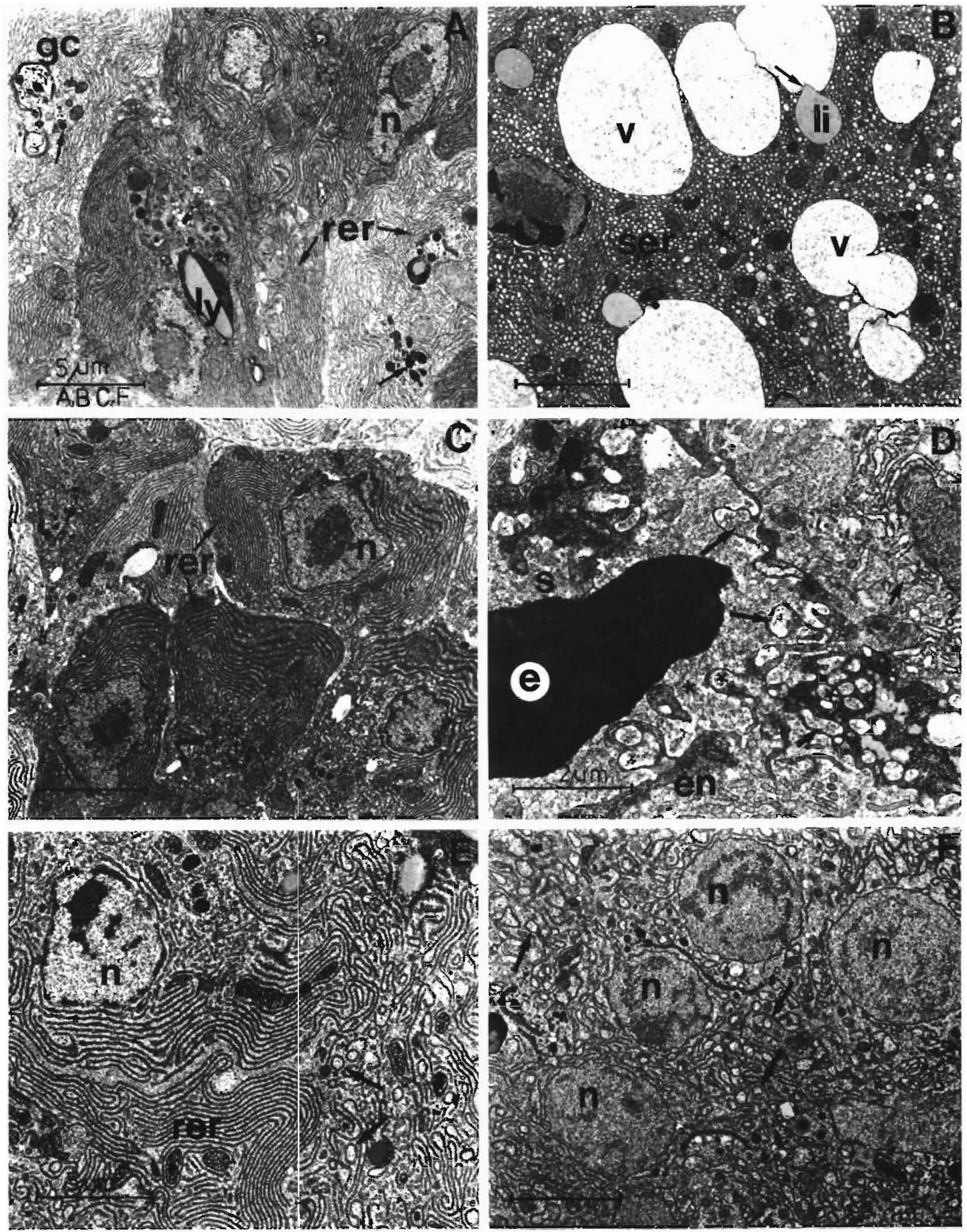

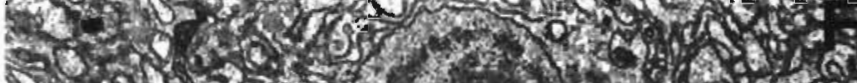

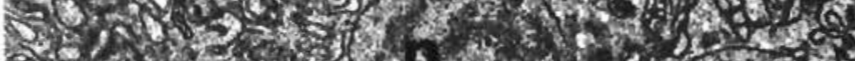

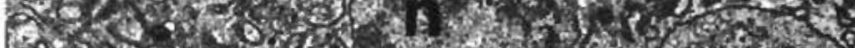

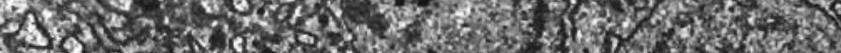

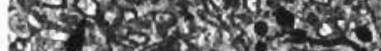

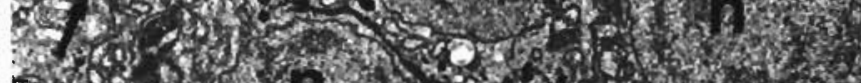

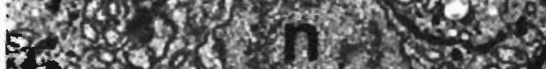
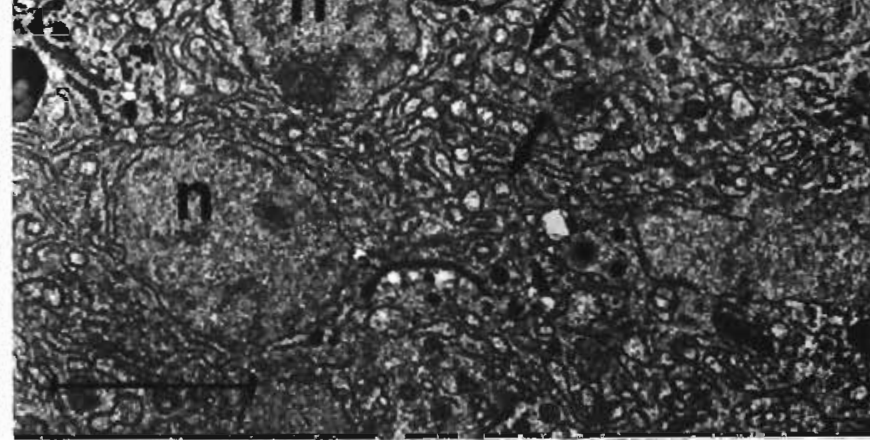

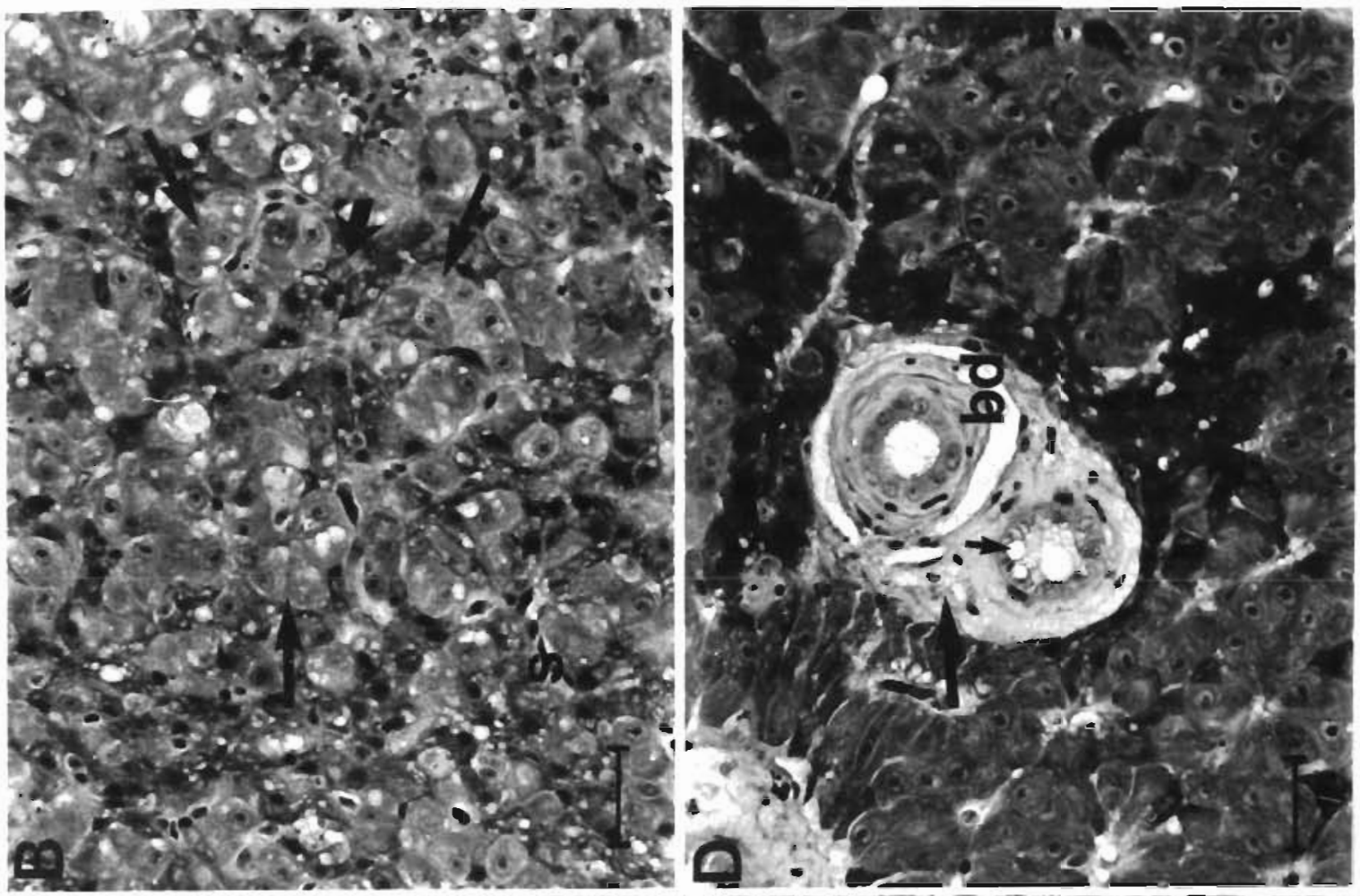

它

过

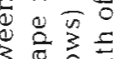
的要

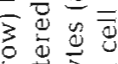

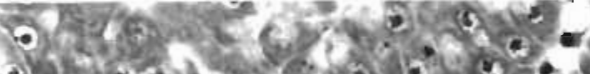

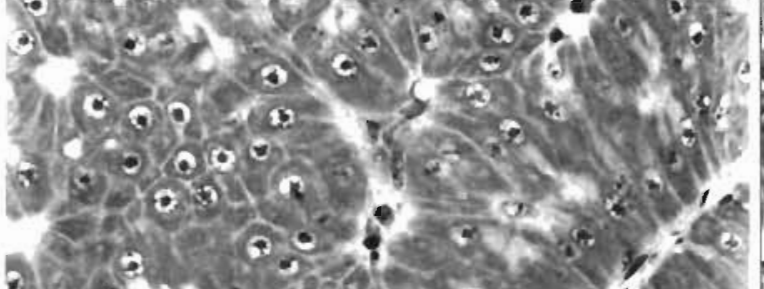

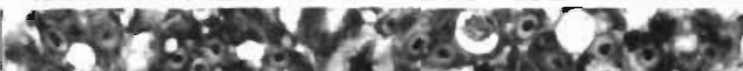
舟

过告嵒

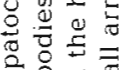

:

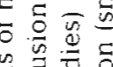

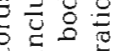

要要

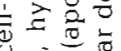

है

年

売员.

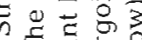

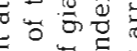

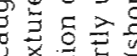

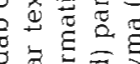

元

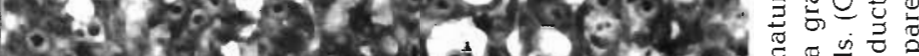

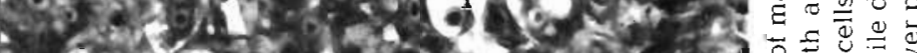

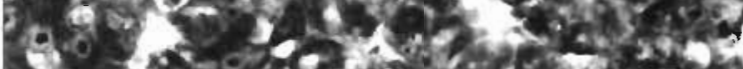
300
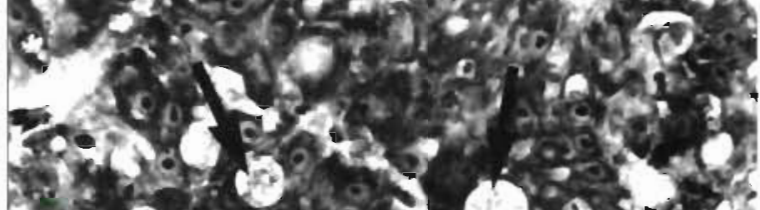

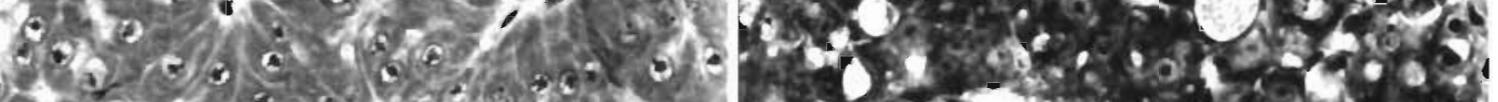

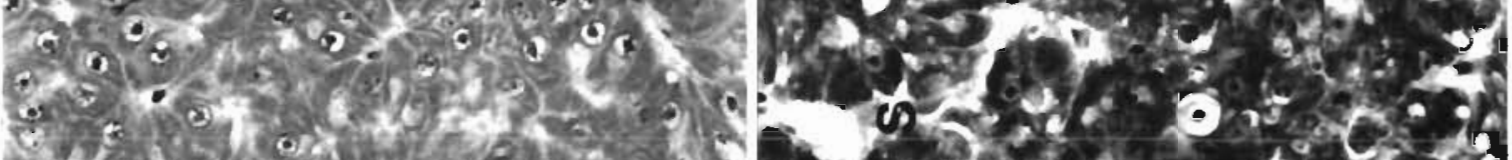

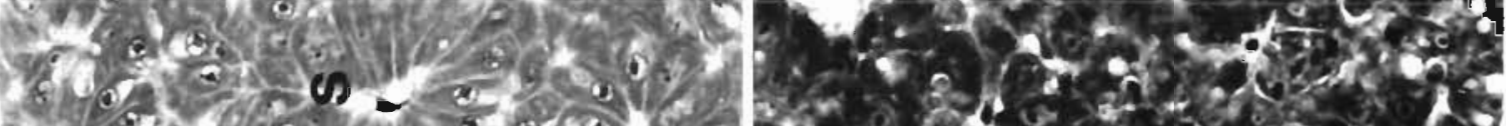

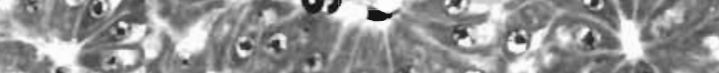

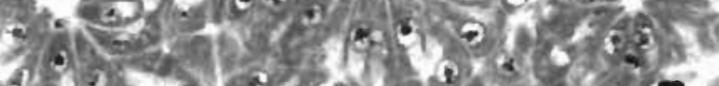
1030 a \& 4.50 .5

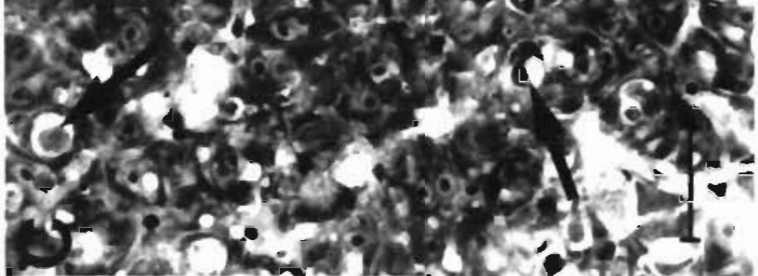

$\$ 0$ 0 I 9 田品 ज佂吾

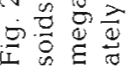




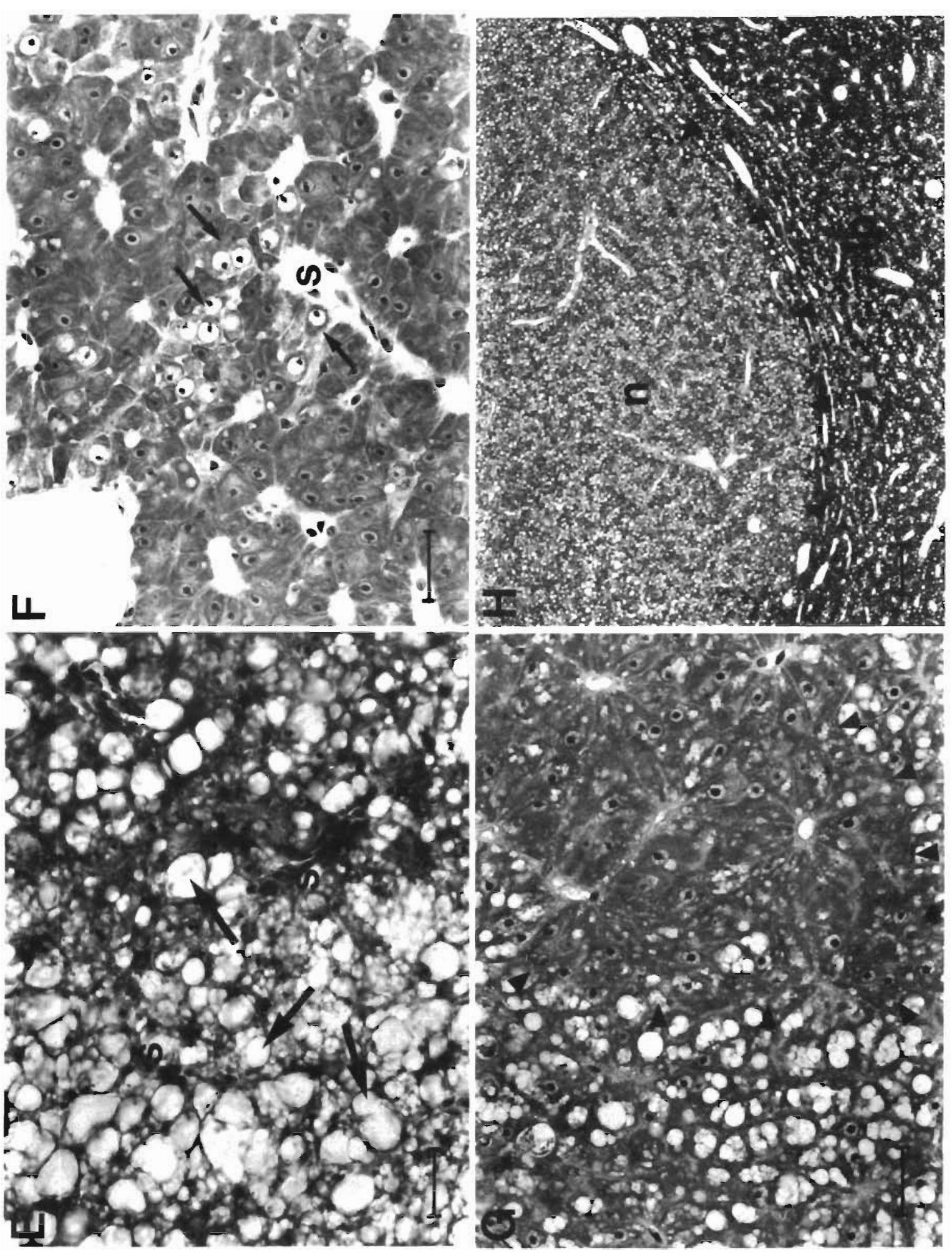

离产造要

范

눙

$\stackrel{0}{\frac{0}{2}}$

的

중

䂞 $\Xi$ 言

웡ㅎㅇㅇㅇㅇ

o

$\stackrel{Q}{=} \cong$

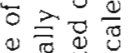

3.

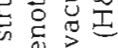

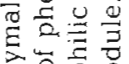

on

证过

000

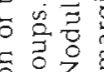

实全焉

兽贯过

¿

원연

कि

उ市

造

워

焉

可局

농ㅁㅇ

0

in

๖

$\stackrel{5}{5}$

心

凷

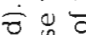

$\Phi$

品

\&

늠

कi 

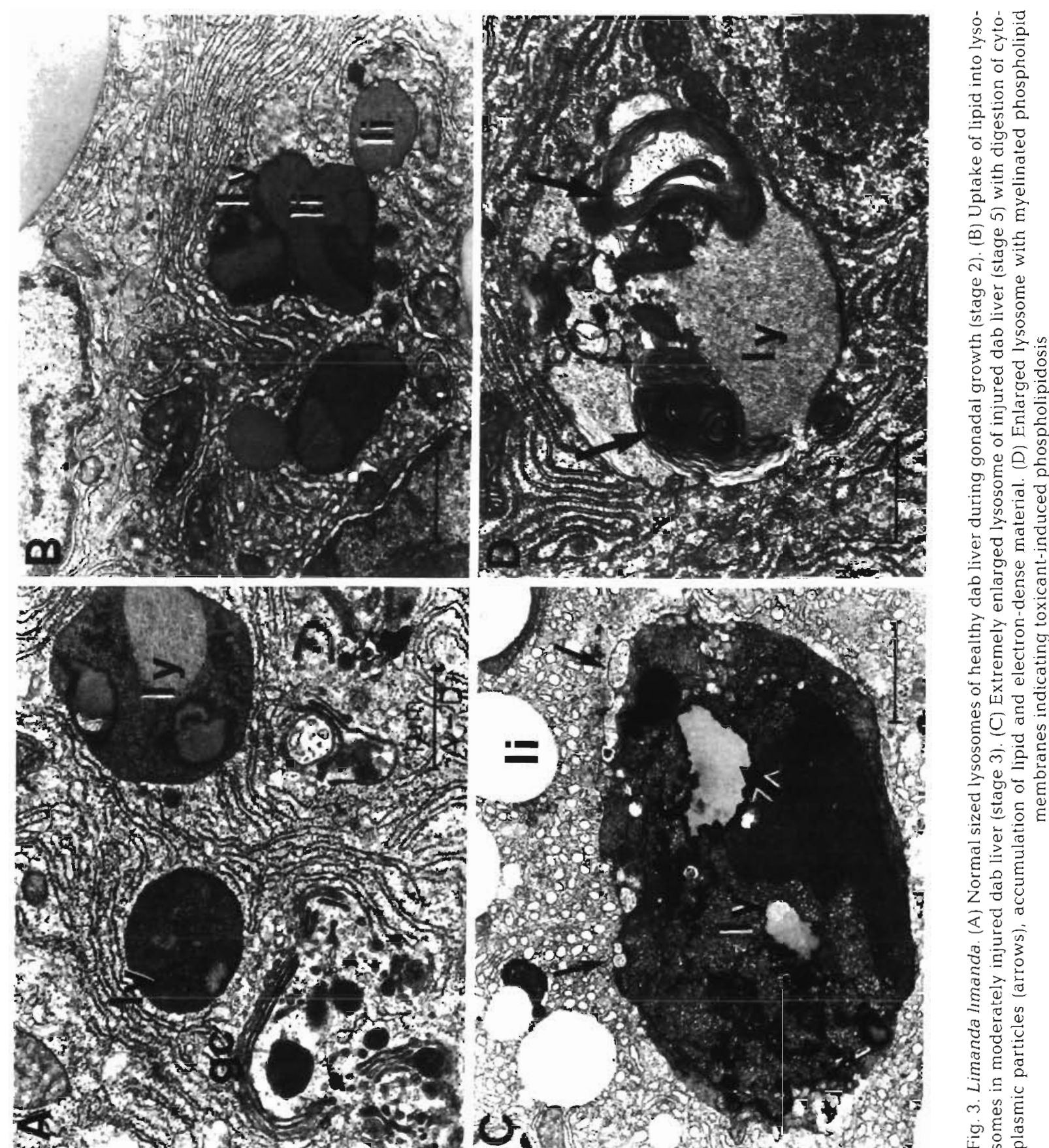
of the hepatocytes. Rough endoplasmic reticulum (rer) and ribosomes occupied the cytoplasm; enlargement and augmentation of mitochondria and a proliferation of the Golgi region with secretion of dense bodies could be seen (Fig. 1A). These findings are consistent with a possible stimulated protein synthesis during vitellogenesis (phospholipoprotein-production as yolk precursor). Comparative studies of immature individuals showed that the dab liver belong to the lipid storage type of the teleost liver according to the criteria of Welsch \& Storch (1973). In immature dab rough endoplasmic reticulum (rer) is restricted to the cell periphery and to the perinuclear region due to cytoplasmic lipid inclusions. Small fields of glycogen, Golgi complexes with 3 to 4 cisternae and few small lysosomes appeared to be characteristic. Results obtained from another study of adult dab during gonadal rest in September revealed basically identical features of the cellular organisation (Köhler unpubl.).

The liver pathologies observed at the light microscopic level in maturing dab along the German Bight transect are summarised according to their co-occurrence and staged in Table 1 . Stages 1 and 2 represent minor changes due to normal cellular turnover and food supply and have to be regarded as healthy (Fig. 2A). Dab liver diagnosed as healthy showed no gross pathologies recorded directly after dissection on board.

First signs of pathological processes as lytic cell death (necrosis) and lipid infiltration around the blood vessels, regarded as a sign for toxic liver injury, were classified as stage 3. Additionally, in single hepatocytes changes of the cell nucleus, cell shape and staining properties indicated megalocytosis and were observed generally in the proximity of sinusoids (Fig. 2B). During gross inspection 5 out of 40 individuals $(12.5 \%)$ showed nodular changes at the organ surface, $<2 \mathrm{~mm}$ diameter, presumably due to localised lipid accumulation. Nodules $>2 \mathrm{~mm}$ were found in 2 out of 40 individuals $(5.0 \%)$ at this stage of liver lesion. Liver changes from stage 3 on were accompanied by increased lipid accumulation in the lysosomes (Fig. 3B).

In stage 4 an increase of larger lipid droplets and expansion of necrotic processes occurred simultaneously. Cell death regularly started around the sinusoids and bile ducts (Fig. 1D). Often, very large vacuoles were seen to be restricted to the parenchymal areas around blood vessels giving the liver a patchy appearance at the gross and light microscopic level (Fig. 2E). Ultrastructurally, such dab livers showed large amounts of vesicular smooth endoplasmic reticulum (ser) with free ribosomes proliferated throughout the cytoplasm. The extremely enlarged 'vacuoles' in perisinusoidal hepatocytes were filled with a fine precipitate presumably taken up by endocytosis from the sinusoids. Fusion of the vacuoles with lipoid droplets obviously caused the macroscopic gravelly impression (Fig. 1B). Typical lysosomes from these livers showed a considerable enlargement and heterogeneity of the ingested and degraded material (Fig. 3C). Gross findings ranged from 4 out of 22 individuals (18.2\%) with nodular or patchy changes $<2 \mathrm{~mm}$ to 2 out of 22 individuals $(9.1 \%)$ with nodular changes $>2 \mathrm{~mm}$. Both stages 3 and 4 were estimated as presumably reversible anomalies after removal of the injurious stimulus

Moderate to numerous globular bodies were seen in the majority of the sections of healthy and reversibly altered livers as shown in Fig. 2C. At the ultrastructural level they were revealed to be so-called giant lysosomes (Councilman bodies) originating from hepatocytes undergoing apoptosis. This type of cell death is described in processes of normal cell turnover and programmed cell death under natural physiological conditions (Wyllie 1981). As this morphological phenomenon was too evident to be neglected, data on the semiquantitative evaluation of the presence of globular bodies during the different stages of liver changes are presented in Fig. 4

Table 1. Limanda limanda. Stages of liver lesions in dab based on the co-occurrence of pathological symptoms and graded according to the extension in tissue sections and their functional/toxicological relevance

1 Normal liver parenchyma

2. Shrinkage of single hepatocytes, occasional perisinusoidal accumulation of small lipid droplets

3. Focal necrosis, megalocytosis of single cells, mostly near blood vessels (increased eosinophily, cytomegaly, nuclear multiplication and polymorphism), moderate, often homogeneous accumulation of small lipid droplets

4. Extension of lytic necrosis around larger blood vessels, large lipid inclusions in patches or homogeneously disturbed, megalocytosis, hyperplasia, increase of multinucleated hepatocytes, initial fibrosis

5. Dissolution of the parenchymal structure, severe steatosis with lytic necrosis, groups of small cells $(1-5)$ with increased nuclear/cytoplasmic ratio and basophily, megalocytosis, nuclear lipid inclusions, fibrosis

6. 'Clear cell' foci and/or basophilic foci ( $>20$ cells) associated with lesions of the stage 4 and 5 - but partly patchy distribution of very large lipid inclusions, no compression of the surrounding tissue, cholangiofibrosis and severe fibrosis around blood vessels

7. Benign neoplasm (liver cell adenoma) as clearly defined areas in the parenchyma displaying lesions of stages 4 , 5 and 6 with compression of the surrounding tissue

8. Malignant neoplasms (liver cell carcinoma) with invasive growth into surrounding tissue of stage 6 , increase of melano-macrophage centres 


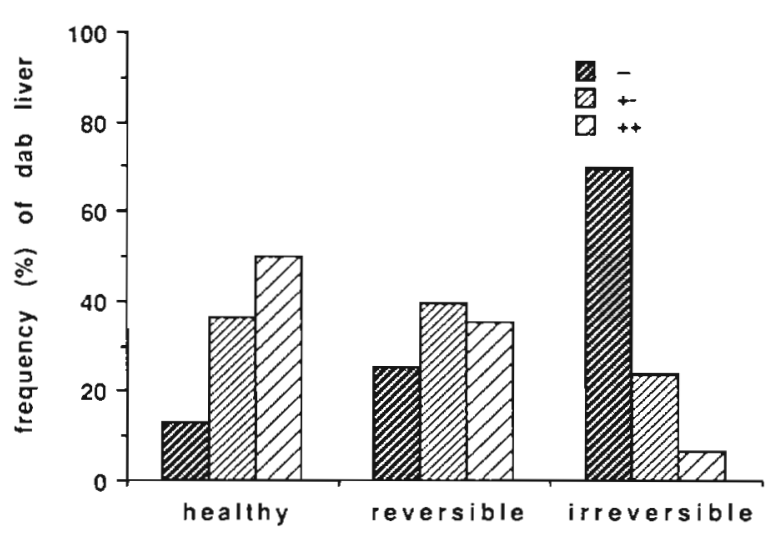

Fig. 4. Limanda limanda. Apoptosis in dab liver (-: no apoptosis; +-: moderate apoptosis; ++: high apoptosis) diagnosed as healthy, reversibly injured and degenerative and irreversibly injured

In stage 5 degenerative processes such as lytic necrosis dominated, often associated with parenchymal areas showing signs of megalocytosis. The first appearance of a new type of phenotypically altered cells, singly or in small groups around the sinusoids, could also be observed. Often, this type of cell was seen adjacent to those hepatocytes which were degenerating in lytic necrosis. The cells were obviously smaller and of a different shape to the other hepatocytes and showed an increase of basophilia. The nuclei were translucent with a prominent nucleolus and the nuclear/cytoplasmic ratio was increased (Fig. 2F). A further increase of connective tissue (fibrosis) around the blood vessels and bile ducts was noted. Some perisinusoidal cells were empty and were reminiscent of spongiotic cells described in other fish species. Signs of toxically induced phospholipidosis in lysosomes, only rarely seen in less severely damaged livers, regularly occurred in stage 5 (Fig. 3D). Liver changes from stage 5 on were termed as degenerative and regarded as possibly irreversible, since lytic necrosis and fatty change dominated; connective tissue was increased and was substituted for normal liver parenchyma. As shown in Fig. 4, at this degree of liver lesions the frequency of apoptotic bodies diminished considerably, inplying that natural physiological cell death was reduced, possibly to compensate for reduced tissue growth. Gross inspection showed nodules $<2 \mathrm{~mm}$ (up to 10 nodules per liver) in 3 out of 25 individuals (12\%) at this stage of lesion while frequency of nodules $>2 \mathrm{~mm}$ remained low with 1 out of 23 individuals ( $4.3 \%$ )

Representative for stage 6 was the presence of foci formed by phenotypically altered cells. The basophilic cell type clearly dominated (Fig. 2G). At the electron microscopic (EM) level these cells were densely packed with parallel stacks of rough endoplasmic reticulum studded with polysomes (Fig. 1C). Foci were randomly distributed throughout the sections but regularly associated to the blood sinusoids. In some livers, foci of apparently empty 'clear' cells or eosinophilic cells were seen. The surrounding liver parenchyma showed symptoms ranging from stage 4 to 5 . Occasionally, transitions of foci of small basophilic cells into larger clearly defined areas composed of a cell type with circular profiles of rough endoplasmic reticulum (rer) was detected at the EM level (Fig. 1E). The cells of these areas, which might be neoplasms, had numerous nuclei and a totally disorganised rer showing sinuous and circular profiles. An increase of grossly visible small nodules $(<2 \mathrm{~mm})$ in up to 16 out of 30 individuals $(53.3 \%$ ) and of larger nodules (>2 mm) in up to 6 out of 30 dab $(20.0 \%)$ was recorded in those dabs whose livers had been histologically diagnosed as stage 6 .

Benign neoplasms originating from hepatocytes (liver cell adenoma) with compression of the surrounding liver tissue were classified as stage 7 (Fig. $2 \mathrm{H}$ ), and tumours revealing initial invasive growth into the adjacent liver parenchyma were classified as malignant neoplasms in stage 8 . Yet, the overall frequency of benign and malignant neoplasms in this age group of dab investigated ( 20 to $25 \mathrm{~cm}$ total length) was low. For this reason no electron microscopic findings are available from these cases. Only in 2 out of the 7 cases, found at the nearshore stations (1 to 6), were these neoplasms already visible as nodules during gross inspection and were larger than $2 \mathrm{~mm}$ up to $4 \mathrm{~mm}$.

\section{Lysosomal changes and liver injury}

Rapid cytochemical techniques were tested for their usefulness in monitoring programmes in concert with parallel histological diagnoses of dab liver anomalies. The purpose of this approach was to check if lysosomal perturbation and accumulation of unsaturated neutral lipids are able to reflect toxicant-induced liver injury. The results of linking the cytochemical measurements with the diagnostic findings of liver lesions in identical individuals are summarised in Fig. 5. Positive significant correlations were observed between the severity of liver lesions and the accumulation of unsaturated neutral lipids (Spearman's rank correlation, $\mathrm{p}<1 \% 2$ tailed). Dab liver diagnosed as healthy (stages 1 and 2) contained only small amounts of unsaturated neutral lipids (Fig. 5A). With the onset of liver injury regarded as reversible (stages 3 and 4 ), a statistically significant increase of neutrallipids (confidence level $>95 \%$ w was evident and remained at identical levels in presumably 'irreversibly' damaged livers (above stage 5). Liver discolouration (data not presented here) was found to be positively correlated to the accumulation of unsatu- 
A

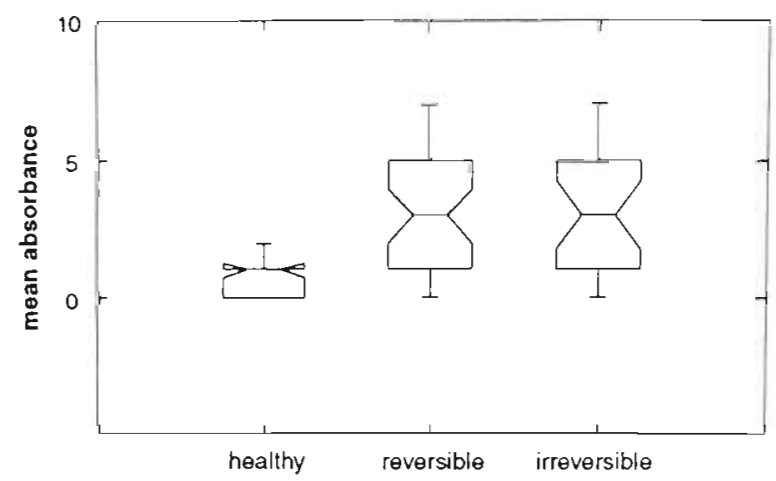

B

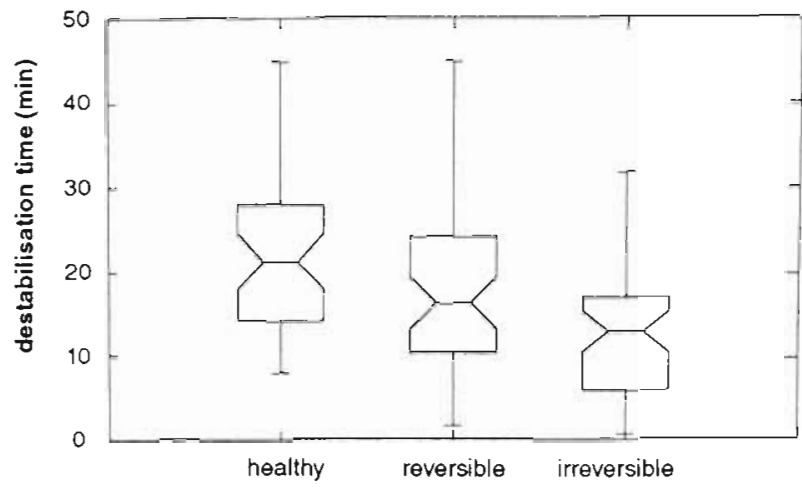

Fig. 5. Limanda limanda. (A) Accumulation of unsaturated neutral lipids and (B) lysosomal membrane stability during the progression of liver lesions. (Median, confidence interval at the $95 \%$ level; hinges: minima, maxima)

rated neutral lipids, as well as to the severity of liver lesions. It is interesting to note that unsaturated lipids accumulated predominantly in the lysosomes as could be detected both in electron micrographs and in cytochemical preparations.

In the lysosomal compartment of dab liver 2 populations of lysosomes were identified by different labilisation periods. One type of lysosome showed a reduced membrane labilisation period of 3 to $4.5 \mathrm{~min}$. Interestingly, no relationships were statistically identified between the degree of liver pathologies, presence of grossly visible liver nodules or neutral lipids and the labilisation time of this type of lysosome. Further, no correlation could be identified between membrane stability of these lysosomes and gonadal maturation. Finally, no statistical differences between the stations of the German Bight transect with respect to this lysosomal population could be detected. Studies on the role and functions of these lysosomes are continuing.

A totally different response was observed in the second type of lysosomes with a lysosomal membrane stability varying between 5 and $30 \mathrm{~min}$. A highly significant correlation between the progression of liver lesions and the breakdown of the lysosomal membrane integrity became evident (Spearman, $x<1 \%, 2$-tailed) (Fig. 5B). In healthy dab liver the acid labilisation time was above 20 min (median). In reversibly injured dab liver the median lysosomal labilisation time decreased to only $15 \mathrm{~min}$, though not differing statistically from the healthy state at the chosen confidence level. However, lysosomal stability of presumably irreversibly damaged dab livers was significantly lower compared to healthy dab liver at the level of confidence of $>95 \%$. The statistical evaluation showed further that the stage of gonadal maturation did not influence the stability of the lysosomal system, the accumulation of neutral lipids or pathological alterations of the liver tissue.

\section{Lysosomal perturbations related to gross and micro- scopic liver pathologies along the German Bight transect}

Highest rates of grossly visible liver nodules $>2 \mathrm{~mm}$, which were additionally recorded during this study, revealed highest incidences at the innermost stations $(1,3 \& 5)$ in up to $50 \%$ of the dab (Fig. 6A). At Stn 6 small grossly visible nodules were seen in only a few specimens, with none at the Stns 7 to 8 . Nodules $>2 \mathrm{~mm}$ recorded according to the ICES recommendations showed incidences in less than $20 \%$ of the dab at the inshore Stns 1, $3 \& 5$. No signs of gross pathological alterations at all were identified at Stns $8 \& 9$ (Fig. 6A).

The frequencies of liver abnormalities detected at the light microscopic level along the German Bight transect are summarised in Fig. 6B, differentiated according to the above criteria of presumably reversible, degenerative irreversible and putatively preneoplastic lesions. The light microscopic inspection showed evidence of pathological liver changes above $80 \%$ in total at the inshore stations $(1,3 \& 5)$ with a significant decrease towards Stn 7 below $50 \%$ and a slight, but not significant increase at Stn 9. At Stn 1, north of the mouth of the Elbe, $48 \%$ of dab showed possibly irreversible liver lesions. Highest rates of the most severe lesion types were noted at Stn 3 in $80 \%$ of individuals with a clear gradient towards the offshore stations. A slight increase with respect to reversible lesions was noted at Stn 9 on the Dogger Bank.

The results obtained from cytochemical measurements of lysosomal perturbations are in accordance with the occurrence of pathological liver changes along the German Bight transect (Fig. 6D). At the most inshore Stn 3, drastically impaired membrane stability of the lysosomal system was found in dab liver. A slightly better lysosomal membrane stability than at Stn 3 was measured at the inner Stn 1 than at Stn 3, 

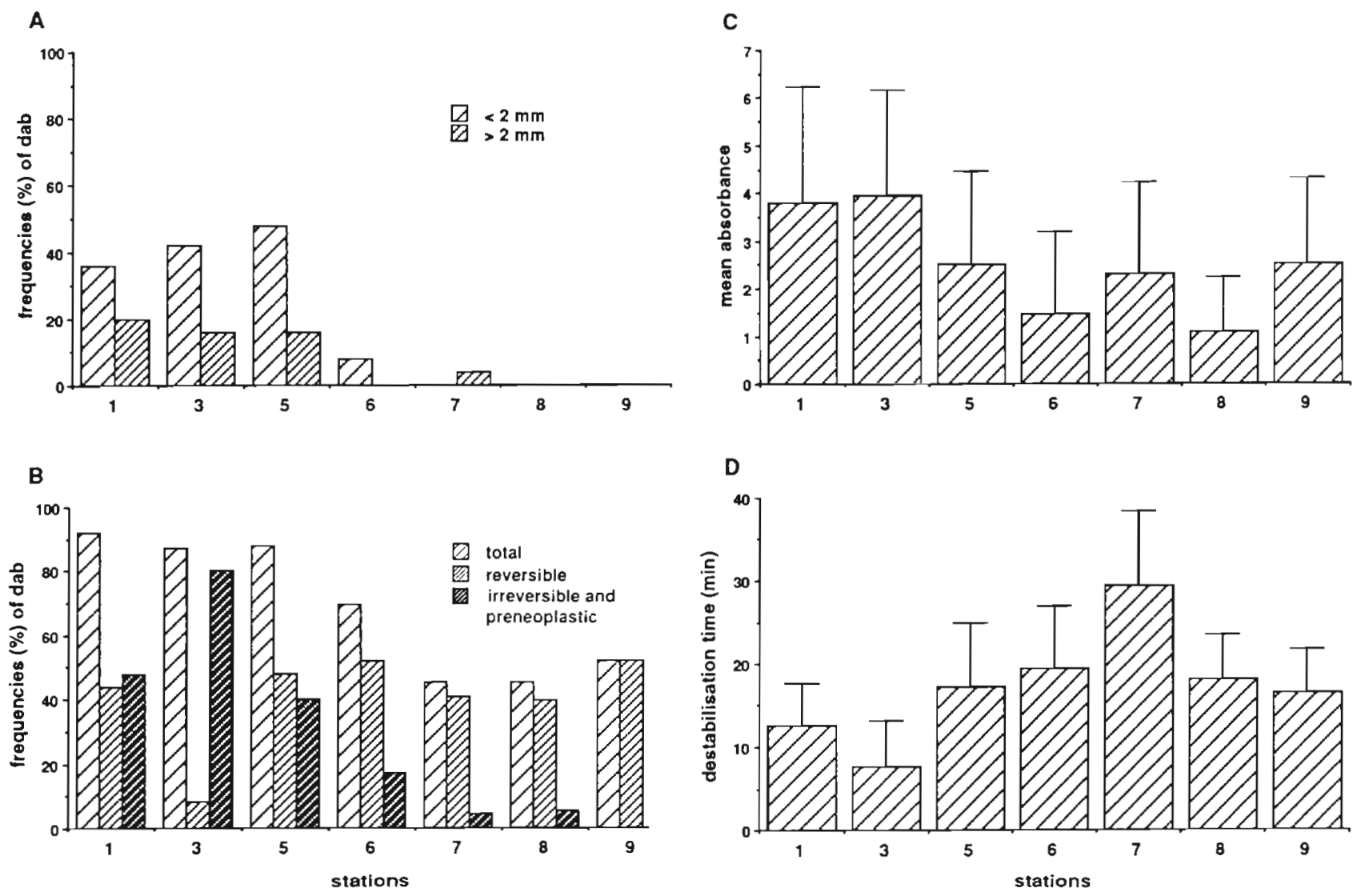

Fig. 6. Limanda limanda. Biological parameters of the liver of dab caught along the German Bight transect (25 individuals per station; $N=175$ ). (A) Frequency of grossly visible liver nodules ( $<2 \mathrm{~mm}$ and $>2 \mathrm{~mm}$ in diameter). (B) Liver histopathology of dab with total frequencies of individuals with liver anomalies and discrimination into reversible and irreversible lesions. (C) Accumulation of unsaturated neutral lipids in dab liver lysosomes. (D) Lysosomal membrane stability determined as the period of acid labilisation $(0,2,4,5,10$ to $45 \mathrm{~min})$ required to fully destabilise the membrane

with a $99 \%$ confidence level (Kruskal-Wallis test). At the further offshore Stns $5,6,8 \& 9$, a significantly higher integrity of the lysosomal membrane $(p<0.1 \%)$ was measured and maximum labilisation periods were found at $\operatorname{Stn} 7$.

At the inshore Stns $1 \& 3$, dab livers contained significantly enhanced levels of unsaturated neutral lipids $(p<0.1 \%)$ compared to the further offshore stations (Fig. 6C). No differences with respect to unsaturated neutral lipids were identified between Stns 5, $7 \& 9$ where relatively enhanced levels were detected compared to Stns $6 \& 8$.

\section{DISCUSSION}

Cytochemical techniques established in mammals, marine mussels and flounder (Bitensky et al. 1973, Moore 1976, Köhler 1990) measuring the lysosornal membrane integrity and pathological lipid accumulation could be easily transferred to dab Limanda li- manda during the Bremerhaven Workshop. Livers of dab indicated changes in the cellular architecture due to the activation of vitellogenic processes during gonadal growth similar to findings in other teleosts (Weis 1972, Peute et al. 1978, Köhler 1991). Nevertheless, the lysosomal system in fish liver obviously appears to be more stable, in relation to the physiological changes during reproduction (Köhler 1991), than is documented for the mussel (Moore et al. 1978), because no correlations could be statistically identified between gonadal development and lipidosis and lysosomal membrane injury.

Parallel diagnosis of cell and tissue pathologies in dab liver showed that lysosomal perturbations sensitively reflected the onset and progression of liver injury comprising focal to extensive lytic necrosis, steatosis, fibrosis, foci and nodules of phenotypically altered cells and neoplasms, as indicated by highly significant correlations between the breakdown of lysosomal stability and the degree of liver lesions. Other studies (1987 to 1990) on Wadden Sea flounder Platichthys 
flesus have shown that lysosomal membrane stability sensitively reflected the onset and progression of liver pathologies to neoplasia (Köhler unpubl.). In the above studies the accumulation of the most toxicologically relevant $\mathrm{PCB}$-congeners (e.g. 101, 118, 138) and $\mathrm{HCH}$ isomers was significantly correlated to decreased lysosomal membrane stability in those regions of the Wadden Sea influenced by the highly contaminated rivers Elbe and Weser.

The accumulation of unsaturated neutral lipids and membrane whorls in lysosomes are an early indicator for chemically induced lipidosis (Klaunig et al. 1979, Lüllmann-Rauch 1979, Hawkes 1980). Linking the data for intralysosomal lipid accumulation and liver pathologies showed that already in reversibly injured dab liver the amount of unsaturated neutral lipids was significantly enhanced. Ultrastructural studies in the liver of an other flatfish species (Platichthys flesus) showed evidence for a key role of the lysosomal system and lipidosis during the development of liver anomalies and in relation to the contaminant burden (Köhler et al. 1986, Köhler 1989, 1990, 1991). Injury of the lysosomal membrane by lipophilic toxic compounds and/or oxyradicals may lead to leakage of the hydrolytic lysosomal enzymes from the lysosomal compartment causing disturbances of cell functions and resulting in degeneration and possibly in neoplasia (Lowe et al. 1981, Moore 1985, 1988, Malins et al. 1988, DiGuilio et al. 1989).

In accordance to the results of lysosomal perturbations and liver pathologies, highest oxyradical production was measured by other workshop participants at the inshore Stn 3 with a decreasing gradient towards the Dogger Bank (Lowe et al. 1992, Moore 1992, Simpson \& Hutchinson 1992). Proliferation of endoplasmic reticulum and ribosomes detected at the subcellular level on the inshore sites of the transect have also been observed during experimental intoxication with PCBs known to be potent inducers of the MFOsystem in other fish species (Hinton et al. 1978, Klaunig et al. 1979, Goksøyr \& Förlin 1992). Along the transect, measurements of endoplasmic reticulum and MFO activity (EROD) in isolated hepatocytes and in homogenised liver tissue coincided with our findings of highest rates of liver injury at the histological and cytochemical level [for details see Moore et al. (1992), Renton \& Addison (1992)].

Intensive transport processes of specific material, identified by Lowe (pers. comm.) as low density lipoproteins, from the blood vessels by endocytosis were associated with extensive enlargement of lysosomal vacuoles. Similar observations were reported after the application of Aroclor 1254 in rainbow trout and of DDT and PCBs in the liver of rats and chicken (Vos \& Koeman 1970, Johnsson et al. 1981). Low density lipoproteins are suspected vehicles of transport of lipophilic xenobiotics also measured in sediments at the inner stations (Moore et al. 1991).

Megalocytic hepatosis, 'clear cell' and basophilic foci, often preceded by steatosis, necrosis and fibrosis, are described in studies of liver tumors of different fish species as putatively preneoplastic lesions caused by experimental exposure to carcinogens or identified in bottom-dwelling fish living on sediments polluted with anthropogenic chemicals (Malins et al. 1985, 1987. 1988, Myers et al. 1987, Hinton et al. 1988, Vethaak \& Rheinallt 1992). Results of an interdisciplinary study (1987 to 1990) of flounder Platichthys flesus caught in the plume of the highly contaminated Elbe and Weser estuaries showed indications that foci of altered hepatocytes are precursor lesions associated with the development of benign and malignant liver cell tumours (Köhler unpubl.). Further support for anthropogenic chemicals as causative agents for liver lesions were obtained from experimental studies on flounder caught at the highly contaminated Elbe river. When kept in clean water and fed with a contaminant-free diet, the liver showed clear signs of regeneration and tissue burdens of organochlorines fell in regenerating livers (Köhler 1989).

The presence of phenotypically altered foci of basophilic hepatocytes, diagnosed at very high rates at the inshore $\operatorname{Stn} 3$, coincided with an overexpression of the ras-oncoprotein found in cellular foci by Moore \& Evans (1992). The authors regard the overexpression of ras oncoproteins as a potential future candidate for a 'preneoplastic biomarker'. However, at present it can be only speculated on a correlational level that phenotypically altered foci are composed of 'initiated' cells which are preneoplastic. Another question needing further attention is how far $17 \beta$-estradiol, causing liver hyperplasia and hypertrophy during vitellogenesis in flatfish (Emmerson \& Emmerson 1976), or other steroid compounds may function as an additional promoter for the development of early preneoplastic lesions in fish, as was shown in mammals (Schulte-Hermann et al. 1981). The preliminary findings for dab liver indicated that apoptosis as a phenomen described in normal physiological cell death (Wyllie 1981) appeared to be inhibited in severely diseased livers with phenotypically altered hepatocytes. Similar results in rat liver after application of hepatocarcinogens (SchulteHermann et al. 1989) suggest that this phenomenon is worth following up in future fish studies.

Correlations of contaminants measured in dab liver with biological parameters have to be interpreted with caution as they were not obtained from identical individuals or at the same sampling time during the Bremerhaven Workshop (Cofino et al. 1992). However highest incidences of adverse biological effects ob- 
served in dab liver along the German Bight transect coincided with a gradient of sediment levels of organochlorines from the nearshore stations towards the more offshore sites (Lohse 1991).

Simultaneous application of gross pathological, histopathological and cytochemical techniques allowed disease processes in the liver to be detected earlier and therefore more sensitively and precisely than gross inspection of the liver For biological effect monitoring it is essential to be able to detect early lesions with the aid of 'bioindicators' before the endpoint of disease is reached in the development of neoplasia. Neoplasia is the result of chronic processes over several years involving different phases such as induction, promotion and progression; thus relating neoplastic change to an actual contamination situation remains difficult due to the migratory habits of certain indicator species.

At present, a 2 yr interdisciplinary study, 'Fish diseases in the North Sea' (German Federal Environmental Agency), on dab is being carried out in order to test the preliminary but promising findings of the Bremerhaven Workshop. Based on these results the measurement of lysosomal perturbations in fish liver will be recommended as an integrative, fast and costeffective biological warning system which could replace highly sophisticated expertise-dependent techniques of histo-pathology in routine monitoring programs.

Acknowledgements. I would like to express my special gratitude to Drs M. N. Moore and D. Lowe (Plymouth Marine Laboratory, UK) for their explanations and training in the use of the lysosomal stability tests during my stay in their laboratory in 1987. The excellent technical assistance of $U$. Singenstroth during the Bremerhaven Workshop and of Sieglinde Bahns in the preparation of the graphs is gratefully acknowledged.

\section{LITERATURE CITED}

Allison, A. C. (1969). Lysosomes and cancer. In: Dingle, J T , Dean, R. T (eds.) Lysosomes in biology and pathology, Vol. 2. H.B. Elsevier/North Holland, Amsterdam, p. $178-204$

Anon. (1989). Methodology of fish disease surveys. Report of an ICES sea going workshop held on U/F Argos, 16-23 April 1988. ICES Coop. Res. Rep. No. 166: 33 pp

Bannasch, P., Enzmann, H., Klimek, F., Weber, E., Zerban, H. (1989). Significance of sequential cellular changes inside and outside foci of altered hepatocytes during hepatocarcinogenesis. Toxicol. Pathol. 17, 4/1. 617-629

Bancroft, J. D. (1967). An introduction to histochemical techniques. Butterworths, London

Bitensky, L., Butcher, R. S., Chayer, J. (1973). Quantitative cytochemistry in the study of lysosomal function. In: Dingle, J. T (ed.) Lysosomes in biology and pathology. Vol. 3. North Holland, American Elsevier, Amsterdam, New York, p. 465-510

Braunbeck, T., Storch, V., Nagel, R. (1989). Sex-specific reactions of liver ultrastructure in zebra fish (Brachydanio rerio) after prolonged sublethal exposure to 4-nitrophenol. Aquat. Toxicol. 14: 185-202

Bückmann, A. (1929). Die Methodik fischereibiologischer Untersuchungen an Meeresfischen. In: Abderhalden, E. (ed.) Handbuch der biologischen Arbeitsmethoden, 9. Urban und Schwarzenberg, Berlin, Wien

Cofino, W. P., Smedes, F., de Jong, S. A., Abarnou, A., Boon, J. P., Oostıngh, I., Davies, I. M., Klungsoyr, J., Wilhelmsen, S., Law, R. J., Whinnett, J. A., Schmidt, D., Wilson, S. (1992). The chemistry programme. Mar. Ecol. Prog. Ser. 91: $47-56$

Diazani, M. U., Ugazio, G. (1978). Lipid peroxidation. In: Slater, T F. (ed.) Biochemical mechanisms of liver injury. Academic Press, London, p. 669-707

Di Guilio, R. T., Washburn, P. C., Wenning, R. J., Winston, G. A., Jewell, C. S. (1989). Biochemical responses in aquatic animals: a review of determinants of oxidative stress. Environ. Toxicol. Chem. 8: 1103-1123

Emmerson, B. K., Emmerson, J. (1976). Protein, RNA and DNA metabolism in relation to ovarian vitellogenic growth in the flounder Platichthys flesus. Comp. Biochem. Physiol. 55B: 315-321.

Frith, C. H., Ward, J. M. (1980). A morphologic classification of the proliferative and neoplastic hepatic lesions in mice. J. environ. Pathol. Toxicol. 3: 329-351

Goksøyr, A. Förlin, L. (1992). The cytochrom P450 system in fish, aquatic toxicology and environmental monitoring. Aquat. Toxicol. 22: 287-312

Hawkes, J. W (1.980). The effects of xenobiotics on fish tissues: morphological studies. Fed. Proc. 39: 3230-3236

Hinton, D. E., Couch, J. A., Teh, S. J., Courtney, L. A. (1988). Cytological changes during progression of neoplasia in selected fish species. Aquat. Toxicol 11:77-112

Hinton, D. E., Klaunig, J E., Lipsky, M. M. (1978). PCBinduced alterations in teleost liver: a model for environmental disease in fish. Mar. Fish Rev. 40: 47-50

Hinton, D. E., Lauren, D. J. (1990). Liver structural alterations accompanying chronic toxicity in fishes: potential biomarkers of exposure. In: McCarthy, J. F., Shugart, L. R. (eds.) Biomarkers of environmental contamination. Lewis Publishers, Boca Raton, p. 17-57

Hogstrand, C., Haux, C. (1991). Binding and detoxification of heavy metals in lower vertebrates with reference to metallothionein. Comp. Biochem. Physiol. 100 C, 1/2: 137-142

Johnsson, H. T., Walker, E. M., Greene, W. R. (1981). Effects of prolonged exposure to dietary DDT and PCB on rat liver morphology. Arch. environ. Contam. Toxicol. 10: $171-183$

Klaunig, J. E., Lipsky, M. M., Trump, B. F., Hinton, D. E. (1979). Biochemical and ultrastructural changes in teleost liver following subacute exposure to PCBs. J. environ. Pathol. Toxicol. 2: 953-963

Köhler, A. (1989). Experimental studies on the regeneration of contaminant induced liver lesions in flounder from the Elbe estuary - steps towards the identification of causeeffect relationships. Aquat. Toxicol. 14: 203-232

Köhler, A. (1990). Identification of contaminant-induced cellular and subcellular lesions in the liver of flounder (Platichthys flesus) caught at differently polluted estuaries. Aquat. Toxicol. 16: 271-294

Köhler, A. (1991). Lysosomal perturbations in fish liver as indicators for toxic effects of environmental pollution. Comp. Biochem. Physiol. 100 C, 1/2: 123-127

Köhler, A., Harms, U., Luckas, B. ( 1986). Accumulation of organochlorines and mercury in flounder - an approach to pollution assessments. Helgoländer Meeresunters. 40: $431-440$ 
Lohse, J. (1991). Distribution of organochlorine pollution in North Sea sediments. Wat. Sci. Tech. 24/10: 107-113

Lowe, D. M., Moore, M. N., Clarke, K. R. (1981). Effects of oil on digestive cells in mussels: quantitative alterations in cellular and lysosomal structure. Aquat. Toxicol. 1: $213-226$

Lowe, D. M., Moore, M. N., Evans, B. M. (1992). Contaminant impact on interactions of molecular probes with lysosomes in living hepatocytes from dab Limanda limanda. Mar Ecol. Prog. Ser. 91. 135-140

Lüllmann-Rauch, R. (1979). Drug-induced lysosomal storage disorders. In: Dingle, J. T., Jaques, P. J., Shaw, 1. H. (eds.) Lysosomes in applied biology and therapeutics, 6 . North Holland Elsevier, Amsterdam, New York, p. 49-121

Malins, D. C., Krahn, M. M., Brown, D. W., Rhodes, L. D., Myers, M. S., McCain, B. B., Chan, S. L. (1985). Toxic chemicals in marine sediment and biota from Mukilteo, Washington: relationship with hepatic neoplasms and other hepatic lesions in English sole (Parophris vetulus). J. nati Cancer Inst. 74: 487-494

Malins, D. C., McCain, B. B., Myers, M. S., Brown, D. W., Krahn, M. M., Roubal, W. T., Schiewe, M. H., Landahl, J. 'T., Chan, S. L. (1987). Field and laboratory studies of the aetiology of liver neoplasms in marine fish from Puget Sound. Environ. Health Perspect. 71: 5-16

Malins, D. C., McCain, B. B., Landahl, J. T., Myers, M. S., Krahn, M. M., Brown, D. W., Chan, S. L., Roubal, W. T (1988). Neoplastic and other diseases in fish in relation to toxic chemicals: an overview. Aquat. Toxicol. 11: 43-67

Moore, M. N. (1976). Cytochemical demonstration of latency of lysosomal hydrolases in digestive cells in the common mussel, Mytilus edulis, and changes induced by thermal stress. Cell Tissue Res. 175: 279-287

Moore, M. N. (1985). Cellular responses to pollutants. Mar Pollut. Bull. 16: 134-139

Moore, M. N. (1988). Cytochemical responses of the lysosomal system and NADPH-ferrihemoprotein reductase in molluscan digestive cells to environmental and experimental exposure to xenobiotics. Mar. Ecol. Prog. Ser. 46: 81-89

Moore, M. N. (1992). Molecular cell pathology of pollutantinduced liver injury in flatfish: use of fluorescent probes. Mar. Ecol. Prog. Ser. 91: 127-133

Moore, M. N., Evans, B. M. (1992). Detection of ras oncoproteins in liver cells of flatfish (dab) from a contaminated site in the North Sea. Mar. environ. Res. (in press)

Moore, M. N., Lowe, D. M., Bucke, D., Dixon, P. (1991) Molecular and cellular markers of pollutant exposure and liver damage in fish. ICES, CM, 1991/E:23

Moore, M. N., Lowe, D. M., Fieth, P. E. M. (1978). Responses of lysosomes in the digestive cells of the common mussel, Mytilus edulis, to sex steroids and cortisol. Cell Tissue Res. 188: $1-9$

Myers, M. S., Rhodes, L. D., McCain, B. B. (1987). Pathologic anatomy and patterns of occurrence of hepatic neoplasms, putative preneoplastic lesions, and other idiopathic hepatic conditions in English sole (Parophrys vetulus) from Puget Sound, Washington. J. natl Cancer Inst. 78(2): $333-362$
Peute, J., van der Gaag M. A., Lambert, J. G. D. (1978). Ultrastructure and lipid content of the liver of zebrafish, Brachydanio rerio, related to vitellogenic synthesis. Cell Tissue Res. 186: 297-308

Pierce, K. V., McCain, B. B., Wellings, S. R. (1978). Pathology of hepatomas and other liver abnormalities in English sole (Parophris vetulus) from the Duwamish River estuary. Seattle, Washington. J. natl Cancer. Inst. 69(6): 1445-1453

Renton, K. W. Addison, R. F. (1992). Hepatic microsomal mono-oxygenase activity and P450IA mRNA in North Sea dab Limanda limanda from contaminated sites. Mar. Ecol. Prog. Ser. 91: 65-69

Schulte-Hermann, R., Ohde, G., Schuppler, J., TimmermannTroisiener, I. (1981). Enhanced proliferation of putative preneoplastic cells in rat liver following treatment with the tumor promoters phenobarbital, hexachlorocyclohexane, steroid compounds and nafenopin. Cancer Res. 41: $2556-2562$

Schulte-Hermann, R., Kraupp-Grasl, B., Bursch, W., Gerbracht, U., Timmermann-Trosiener, I. (1989). Effects of non-genotoxic hepatocarcinogens phenobarbital and nafenopin on phenotype and growth of different populations of altered foci in rat liver. Toxicol. Pathol. 17: $642-650$

Simpson, M. G., Hutchinson, T. H. (1992). Toxicological pathology of dab Limanda limanda along pollution gradients in the southern North Sea. Mar. Ecol. Prog. Ser. 91: $155-161$

Staiger, G. R. (1974). Light microscopic demonstration of drug-induced myelin bodies in the liver of rats. Experientia 30: 385-386

Stegeman, J. J., Lech, J. J. (1991). Cytochrom P-450 monooxygenase systems in aquatic species: carcinogen metabolism and biomarkers for carcinogen and pollutant exposure. Environ. Health Perspect. 90: 93-100

Storch, V., Stählin, W., Juraio, J. V. (1983). The effect of different diets on the ultrastructure of hepatocytes of Chanos chanos fry (Chanidae: Teleostei): an electron microscopic and morphometric analysis. Mar. Biol. 74: 101-104

Vethaak, A. D., ap Rheinallt, $\Upsilon$ (1992). Fish disease as monitor for marine pollution: the case of the North Sea. Rev. Fish. Biol. Fish. 2: 1-32

Vos, J. G., Koeman, J. H. (1970). Comparative toxicologic study with polychlorinated biphenyls in chickens with special reference to porphyria, edema formation, liver necrosis, and tissue residues. Toxicol. appl. Pharmacol. 17: $656-672$

Welsch, U., Storch, V. (1973). Enzyme histochemical and ultrastructural observations on the liver of teleost fish. Arch. Histol. Jpn 36: 21-27

Weis, P. (1972). Hepatic ultrastructure in two species of normal, fasted and gravid teleost fish. Am. J. Anat. 133: $317-332$

Wyllie, A. H. (1981). Cell death: a new classification separating apoptosis from necrosis. In: Bowen, I. D., Lockshin, R. A. (eds.) Cell death in biology and pathology. Chapman and Hall, London, New York, p. 9-33

Winston, G. W (1991). Oxidants and antioxidants in aquatic animals. Comp. Biochem. Physiol. 100 C, 1/2: 173-176 